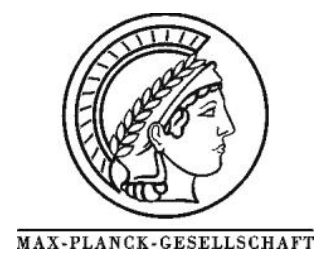

\title{
Pd on carbon nanotubes for liquid phase alcohol oxidation
}

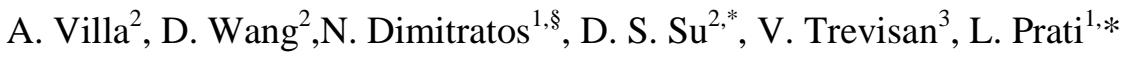 \\ ${ }^{1}$ Università di Milano, Dipartimento CIMA “L.Malatesta”, via Venezian 21, I-20133Milano,Italy \\ ${ }^{2}$ Department of Inorganic Chemistry, Fritz Haber Institute of the Max Planck Society, Faradayweg 4-6, \\ D-14195 Berlin, Germany \\ ${ }^{3}$ Università di Venezia, Dipartimento di Chimica, Dorsoduro 2137, I-30123Venezia, Italy
}

* Corresponding author: e-mail dangsheng@ @ fhi-berlin.mpg.de,

Received: 7 October 2008, Published Online: 29 Jan 2009; Available online 17 July 2009

\begin{abstract}
Pd nanoparticles supported on carbon nanotubes (CNTs) showed a higher selectivity than Pd nanoparticles supported on activated carbon (AC) in the liquid phase oxidation of benzylic alcohol to benzaldehyde. Under solventless conditions a significant improvement in selectivity was observed for Pd/CNTs, whereas using Pd/AC a considerable over-oxidation of benzaldehyde was observed. Differently from other solvents cyclohexane improved significantly the selectivity to benzaldehyde for both catalysts. Characterisation by means of transmission electron microscopy revealed differences in metal dispersion between $\mathrm{Pd} / \mathrm{AC}$ and $\mathrm{Pd} / \mathrm{CNTs}$ that can be ascribed to textural, chemical and physical differences between Active Carbon and Carbon Nanotubes. The higher activity in the case of Pd on AC than on CNTs can be attributed to the improved Pd dispersion in the first case.

On recycling Pd/CNTs resulted more stable (activity loss 50\% in 7 runs) than Pd/AC (activity loss $70 \%$ in 7 runs) even a structural change of catalysts after reaction is observed. The Pd leaching and particle coalescence are the main reasons for the loss of activity. An extraordinary improving of catalyst life has been observed by alloying the Pd nanoparticles with Au, When CNTs are used as support the strong Pd leaching can be greatly limited and the activity/selectivity maintained at least for 8 runs.
\end{abstract}

Keywords: Alcohol oxidation; Palladium on carbon nanotubes; Gold-palladium catalyst

\section{Introduction}

Metal catalyzed alcohol oxidation in the liquid phase using oxygen as the oxidant represents a well known interesting process, but its industrial exploitation was limited by the strong deactivation [1]. Several metals (ruthenium, platinum, palladium and gold) have been used as monometallic catalysts, in some cases with modifier (like $\mathrm{Bi}, \mathrm{Pb}$ ) [25]. The main requirement for a high selectivity and long durability has not been yet achieved. Moreover, a variety of experimental conditions have been tested: from solventless to organic solvents or aqueous conditions. It has been observed that basic conditions improved the activity and the durability, probably due to a prolonged catalyst life. However under basic conditions the selectivity to aldehyde in the alcohol oxidation decreased in favour of the corresponding carboxylic acid (carboxylate).
From an industrial point of view carbonaceous supports are preferable because of the facile recovery of precious metals by burning off the support. Recently, there is a growing interest in the use of CNTs as catalyst supports for metal nanoparticles in many catalytic applications; for example, CNTs supported platinum nanoparticles are used as electrocatalyst in proton-exchange membrane fuel cells [6,7]. Moreover Ni [8,9] and Pd [10] nanoparticles decorated CNTs were used for hydrogen storage and for hydrogen sensing. In addition, $\mathrm{Pd}$ [11], Pt and $\mathrm{Ru}$ [12] metal nanoparticles supported on CNTs show a high catalytic activity in the liquid phase hydrogenation of cinnamaldehyde. However, only few reports on the use of CNTs instead of the widely used AC can be found in the literature. For example, Corma et al. [13] showed that Pd nanoparticles immobilised on CNTs are more active than the one supported on AC in the Heck reaction of styrene and iodobenzene and for the Suzuki coupling of phenylboronic and iodobenzene. They assigned the high activity to the differ- 
ent particle size obtained for the different supports. They showed that the $\mathrm{Pd} / \mathrm{AC}$ is more active than $\mathrm{Pd} / \mathrm{CNT}$ s for the aerobic oxidation of cinnamyl alcohol in ethanol. Moreover Karousis et al. [14] reported higher activity of CNTs supported metal nanoparticles with respect to AC supported ones in the hydrogenation of methyl-9-octadecenoate and 2-methyl-2-pentenal. They concluded that the high catalytic performance of CNTs supported Pd is due to the large active surface of metallic palladium.

In the present work we report on the catalytic activity of CNTs and AC supported Pd nanoparticles prepared by colloidal method using PVA as protective agent [15] in the liquid phase oxidation of benzyl alcohol with the aim of preserving a high selectivity to aldehyde but enhancing the catalyst activity and reusability. Different groups showed that adding Au to Pd catalysts has a beneficial effect in the alcohol oxidation, improving not only the catalytic activity and selectivity to the desired product [16], but also the resistance to the deactivation [17-19]. We recently set up a two step methodology allowing the preparation of uniformly alloyed bimetallic $\mathrm{Au}_{60}-\mathrm{Pd}_{40}$ catalyst supported on activated carbon [15]. With the same procedure we prepared a bimetallic Au-Pd catalyst supported on CNTs.

\section{Experimental Section}

\subsection{Materials}

$\mathrm{Na}_{2} \mathrm{PdCl}_{4}$ and $\mathrm{NaAuCl}_{4} \cdot 2 \mathrm{H}_{2} \mathrm{O}$ were from Aldrich (99.99\% purity), activated carbon from Camel (X40S; SA = $900-1100 \mathrm{~m}^{2} / \mathrm{g} ; \mathrm{PV}=1.5 \mathrm{ml} / \mathrm{g}$ ) and carbon nanotubes from Bayern Materials Science AG (Baytubes C150P; SA $=30$ $\mathrm{m}^{2} / \mathrm{g}$; internal diameter 13-16 nm, length 1-10 $\left.\mu \mathrm{m}\right) . \mathrm{NaBH}_{4}$ of purity > 96\% from Fluka, polyvinylalcohol (PVA) (Mw $=13,000-23,000$ 87-89\% hydrolysed,) from Aldrich were used. Gaseous oxygen from SIAD was $99.99 \%$ pure.

\subsection{Catalyst preparation}

\subsubsection{Monometallic catalysts}

Pd sol: $\mathrm{Na}_{2} \mathrm{PdCl}_{4} \cdot 2 \mathrm{H}_{2} \mathrm{O}(0.043 \mathrm{mmol})$ and PVA solution $2 \%$ wt $(880 \mu \mathrm{l})$ were added to $130 \mathrm{ml}$ of $\mathrm{H}_{2} \mathrm{O}$. After 3 min, $\mathrm{NaBH}_{4}$ solution $(860 \mu \mathrm{l})$ was added to the yellowbrown solution under vigorous magnetic stirring. The brown $\operatorname{Pd}(0)$ sol was immediately formed. An UV-visible spectrum of the palladium sol was recorded for ensuring the complete reduction of Pd (II).

Within few minutes from their generation, the colloids (acidified at $\mathrm{pH}$ 2, by sulphuric acid) were immobilised by adding carbon under vigorous stirring. The catalyst has been filtered washed for several times to ensure the removal of the material arising from the reduction treatment. The samples were dried at $353 \mathrm{~K}$ for $2 \mathrm{~h}$. The amount of support was calculated to obtain a final metal loading of $1 \%$ wt.

\subsubsection{Bimetallic catalyst}

Solid $\mathrm{NaAuCl}_{4} \cdot 2 \mathrm{H}_{2} \mathrm{O}(0.072 \mathrm{mmol})$ was dissolved in $140 \mathrm{ml}$ of water (final $10^{-4} \mathrm{M}$ ) and $0.706 \mathrm{ml}$ of PVA (2\% w/w) was added (Au/PVA 1:1 wt/wt). The yellow solution was stirred for 3 minutes and $2.9 \mathrm{ml}$ of $0.1 \mathrm{M} \mathrm{NaBH}_{4}$ $\left(\mathrm{Au} / \mathrm{NaBH}_{4} 1: 3 \mathrm{~mol} / \mathrm{mol}\right)$ was added under vigorous magnetic stirring. The ruby red $\mathrm{Au}(0)$ sol was immediately formed. An UV-visible spectrum of the gold sol was recorded to check the complete $\mathrm{AuCl}_{4}{ }^{-}$reduction and the formation of Plasmon peak. Within few minutes of sol generation, the gold sol was immobilised by adding carbon nanotubes (acidified until pH 2 by sulphuric acid) under vigorous stirring. The amount of support was calculated as having a gold loading of $0.73 \%$ wt when $\mathrm{Au} / \mathrm{Pd}$ was prepared. After $2 \mathrm{~h}$ the slurry was filtered, the catalyst was thoroughly washed with distilled water (neutral mother liquors). ICP analyses were performed on the filtrate using a Jobin Yvon JV24 to verify the total metal loading on the support. The $\mathrm{Au} / \mathrm{CNTs}$ was then dispersed in $140 \mathrm{ml}$ of water; $\mathrm{Na}_{2} \mathrm{PdCl}_{4}(0.048 \mathrm{~mol})$ and $0.225 \mathrm{ml}$ of PVA solution $(0.2 \% \mathrm{w} / \mathrm{w})(\mathrm{Au} / \mathrm{PVA} 1: 1 \mathrm{wt} / \mathrm{wt})$ were added. $\mathrm{H}_{2}$ has been bubbled $(50 \mathrm{ml} / \mathrm{min})$ under atmospheric pressure and room temperature for $2 \mathrm{~h}$. After additional $18 \mathrm{~h}$, the slurry was filtered, the catalyst was thoroughly washed with distilled water. ICP analyses were performed on the filtrate using a Jobin Yvon JV24 to verify the metal loading on the support. $1 \%$ wt was the total metal loading.

\subsection{Catalytic test}

The reactions were carried out in a thermostatted glass reactor $(30 \mathrm{ml})$ provided with an electronically controlled magnetic stirrer connected to a large reservoir (5000 $\mathrm{ml})$ containing oxygen at $2 \mathrm{~atm}$. The oxygen uptake was followed by a mass flow controller connected to a PC through an A/D board, plotting a flow/time diagram. The oxidation experiments were carried out in solventless or in the presence of a solvent $(0.0125 \mathrm{~mol}$ substrate, Substrate $/$ Metal $\left.=3000(\mathrm{~mol} / \mathrm{mol}), 80{ }^{\circ} \mathrm{C}, p \mathrm{O}_{2}=2 \mathrm{~atm}\right)$. In the case of organic solvent, periodic removal of samples from the reactor was performed, whereas in the case of water solvent, after the end of the reaction the catalyst was filtered off and the product mixture was extracted with $\mathrm{CH}_{2} \mathrm{Cl}_{2}$. Recoveries were always $98 \% \pm 3$ with this procedure. For the identification and analysis of the products a GC-MS and GC (a Dani 86.10 HT Gas Chromatograph equipped with a capillary column, BP21 $30 \mathrm{~m} \times 0.53 \mathrm{~mm}$, $0.5 \mu \mathrm{m}$ Film, made by SGE), were used by comparison of the authentic samples. For the quantification of the reactant-products the external calibration method was used. 


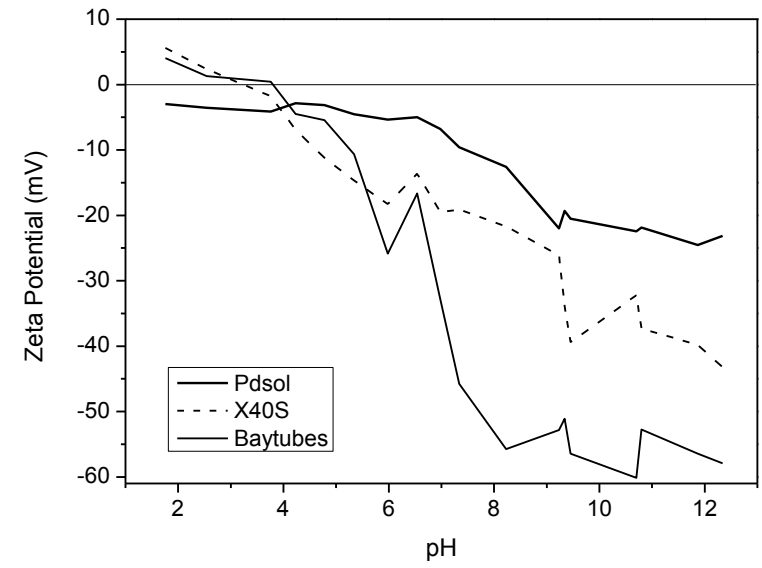

Fig. 1: Zeta potential measurement.

\subsection{Characterisation}

\subsubsection{Sol characterisation}

UV-visible spectra of sols were performed on HP8452 and HP8453 Hewlett-Packard spectrophotometers in $\mathrm{H}_{2} \mathrm{O}$ between 190 and $1200 \mathrm{~nm}$, in a quartz cuvette.

\subsubsection{Catalyst characterisation}

a) The metal content was checked by ICP analysis of the filtrate or alternatively directly on catalyst after burning off the carbon, on a Jobin Yvon JY24.

b) Morphology and microstructures of the catalysts were characterised by TEM. The powder samples of the catalysts were ultrasonically dispersed in ethanol and mounted onto copper grids covered with holy carbon film. A Philips CM200 FEG electron microscope, operating at $200 \mathrm{kV}$ and equipped with a Gatan imaging filter, GIF Tridiem, was used for TEM observation. EDX analysis was performed in the same microscope using a DX4 analyzer system (EDAX).

c) Z-potential measurements were performed on Zetasizer nano ZS/MPT-2 from Malvern. $10 \mathrm{mg}$ of support was dispersed in $50 \mathrm{ml}$ of distilled water and sonicated for $10 \mathrm{~min}$. The support was then removed by filtration and the solution was ready for zeta potential measurements. For the colloidal metal solution no pre-treatment was used before the measurement.
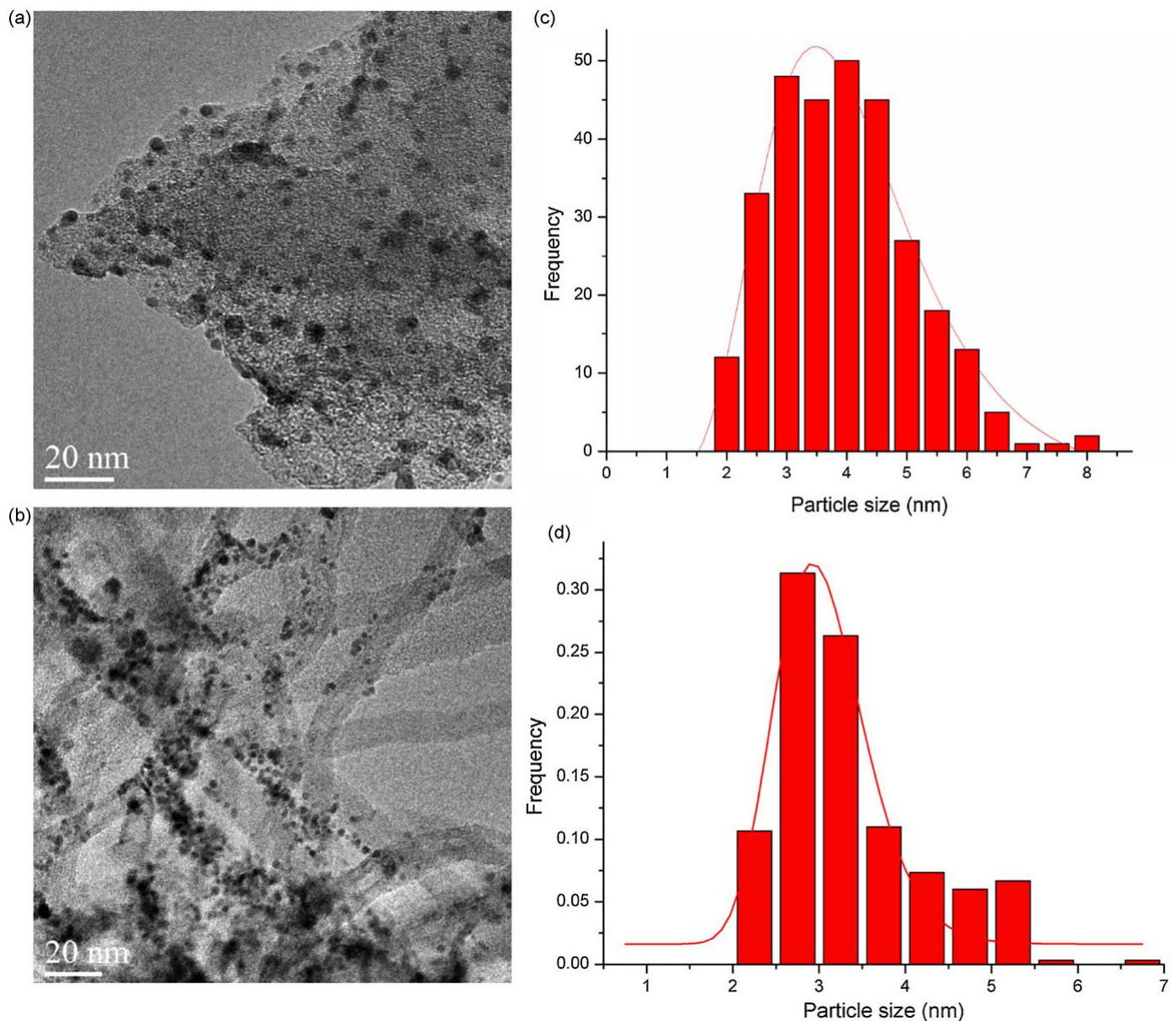

Fig. 2: The TEM overview images of a)Pd/AC and b)Pd/CNTs, (c) and (d) the Pd particle size distribution of the two catalysts, respectively. 
Table 1: Statistical Median and Standard Deviation of particle size analysis for Pd and Au/Pd catalysts

\begin{tabular}{lllllll}
\hline & Pd/AC fresh & Pd/AC after 7 russ & Pd/CNTs fresh & Pd/CNTs after 8 runs & Au-Pd/AC fresh & Au-Pd/CNTs fresh \\
\hline Statistical meatin (nm) & 394 & 5.27 & 3.35 & 6.44 & 3.41 & 3.53 \\
Standard deviation, $\sigma$ & 1.15 & 1.42 & 0.87 & 2.56 & 0.69 & 0.78 \\
\hline
\end{tabular}

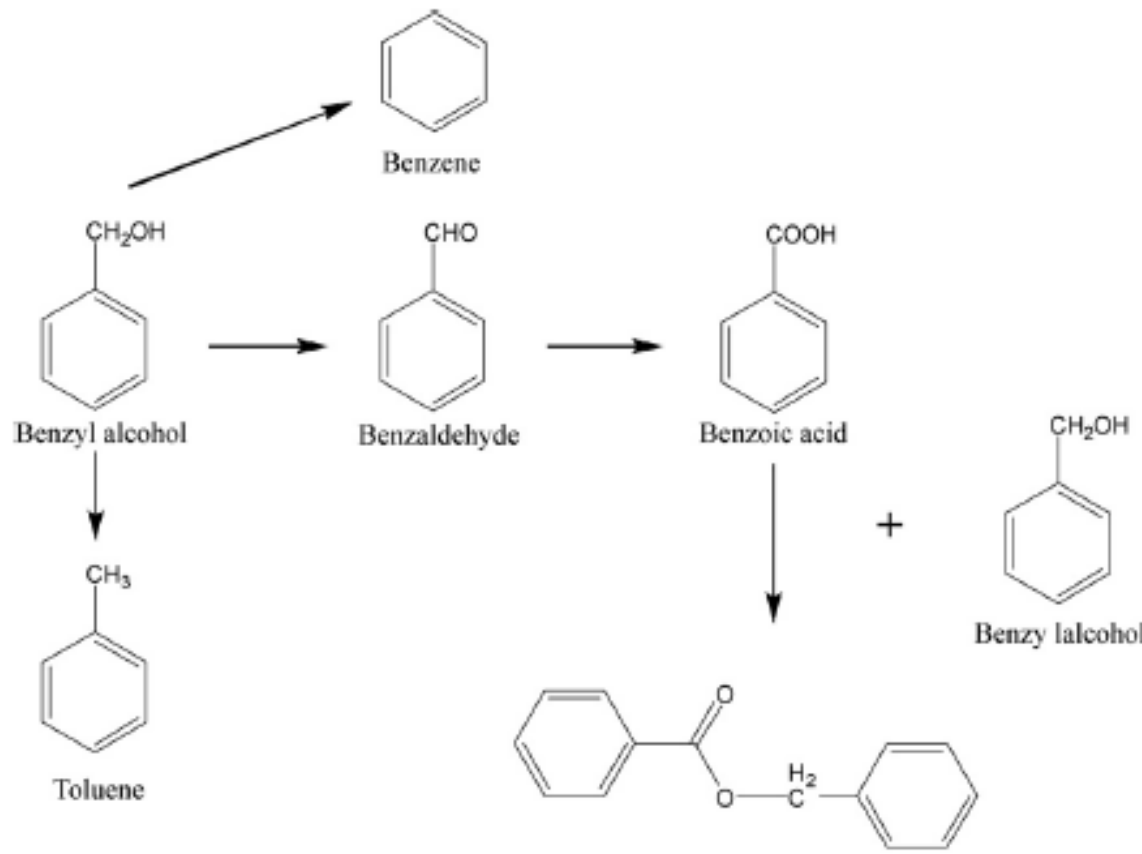

Benzyl benzoate

Scheme 1. Possible reaction scheme for benzyl alcohol oxidation.

\section{Results and Discussion}

\subsection{Catalytic activity of $P d$ supported on $A C$ and CNTs}

$\mathrm{AC}$ is a widely used catalyst support for liquid phase reaction. However recent literature disregards $\mathrm{AC}$ as the support for alcohol oxidation; the most used supporting materials are oxides despite their disadvantage in precious metal recovery. We concentrated on benzylic alcohol to benzaldehyde selective oxidation which is an important reaction from an industrial point of view and has been studied under a variety of reaction conditions using different catalytic systems.

We synthesized $1 \%$ wt Pd/AC or CNT via the sol immobilisation method $\left(\mathrm{NaBH}_{4} / \mathrm{PVA}\right)$. The palladium metal sol was generated by $\mathrm{NaBH}_{4}$ reduction of $\mathrm{Na}_{2} \mathrm{PdCl}_{4}$ salt in the presence of a protective agent (polyvinyl alcohol, PVA) which provides electrostatic as well as sterical stabilization of the nanoparticles. Pd-sol appeared negatively charged at any $\mathrm{pH}$ of the solution (Figure 1). The AC and CNT auto-generates different basic $\mathrm{pH}$ (9.18 and 10.28 respectively) but acidic groups determined by the Boehm method [20] revealed a similar density of carboxylic groups $(9.74$ and $9.89 \mathrm{mmol} / \mathrm{g}$ ). Thus the support suspension was previously acidified $(\mathrm{pH}=2)$ in order to create a positive electrostatic attraction between the support and the protected metal particles (Figure 1). In principle the immobilisation of preformed Pd nanoparticles assured a similar particle size distribution on different support.

Figures $2 \mathrm{a}$ and $2 \mathrm{~b}$ show the TEM overview images of the as prepared $\mathrm{Pd} / \mathrm{AC}$ and $\mathrm{Pd} / \mathrm{CNTs}$, respectively. The histograms of the particle size distribution for $\mathrm{AC}$ and CNTs supported Pd particles are shown in Figures $2 \mathrm{c}$ and $2 \mathrm{~d}$, respectively. Fitting by Log-Normal function, the $\mathrm{Pd} / \mathrm{AC}$ was found to have median size of $3.9 \mathrm{~nm}$ and the $\mathrm{Pd} / \mathrm{CNTs}$ of $3.4 \mathrm{~nm}$ (Table 1). However, though Pd particles on CNTs have smaller size, Pd particles on AC exhibit a more homogeneous distribution. In fact for Pd/CNTs, some CNTs were found without Pd particles, while many Pd particles are observed in aggregates. This difference could be attributed to a different and inhomogeneous distribution of chemical groups on the CNTs surface respect to AC ones.

The catalysts were tested in the liquid phase oxidation of benzyl alcohol. This reaction has been widely studied in the literature using a variety of experimental conditions. In the present study we tested the most promising solventless reaction, the most benign reaction in water although in the literature toluene represents the most common solvent used [21]. However, as toluene is a possible by-product in the benzyl alcohol oxidation (Scheme 1), we 
Table 2. Benzyl alcohol oxidation in the presence of supported $1 \%$ wt Pd

\begin{tabular}{|c|c|c|c|c|c|c|}
\hline \multirow[t]{2}{*}{ Solvent } & \multicolumn{2}{|c|}{$\begin{array}{l}\text { Selectivity } \\
\text { taluene" }\end{array}$} & \multicolumn{2}{|c|}{$\begin{array}{l}\text { Selectivity to } \\
\text { berkaldehyde }\end{array}$} & \multicolumn{2}{|c|}{$\operatorname{TOF}\left(\mathrm{h}^{-1}\right)^{\mathrm{b}}$} \\
\hline & Pd $/ A C$ & $\mathrm{Pd} / \mathrm{CN}$ I & $\mathrm{Pd} / \mathrm{AC}$ & $\mathrm{Pd} / \mathrm{CNT}$ & Pd $/ A C$ & $\mathrm{Pd} / \mathrm{CN}$ \\
\hline Neat & 33 & 17 & 61 & 78 & 2980 & 1412 \\
\hline 258 water & 25 & 25 & 71 & 73 & 1485 & 730 \\
\hline 506 water & 30 & 41 & 67 & 57 & 1227 & 506 \\
\hline $75 \%$ water & 36 & 37 & 62 & 59 & 850 & 554 \\
\hline 206 cydohexane & 29 & 24 & 67 & 74 & 2846 & 1462 \\
\hline 506 cydohexane & 23 & 3 & 74 & 92 & 1482 & 1390 \\
\hline sot cydohexane & 8 & 8 & 88 & 88 & 490 & 493 \\
\hline
\end{tabular}

Reaction condition: alcohol/metal 3000/1 (mol/mol), $80^{\circ} \mathrm{C}, \mathrm{pO}_{2} 2$ atm, $1250 \mathrm{rpm}$

${ }^{a}$ Selectivity at $90 \%$ conversion

${ }^{\mathrm{b}}$ TOF calculated after 15 min of reaction

avoided its use and checked a different organic solvent (cyclohexane). Table 2 reports the results of Pd supported on $\mathrm{AC}$ and CNT using different amounts of each solvent. The experimental conditions were maintained constant (0.0125 mol substrate, alcohol/metal 3000/1 ( $\mathrm{mol} / \mathrm{mol}$ ), $80^{\circ} \mathrm{C}, \mathrm{pO}_{2} 2 \mathrm{~atm}, 1250 \mathrm{rpm}$ ) just varying the amount of solvent.

The screening of activity of Pd on AC (Table 2) revealed that, referring to solventless conditions, water addition causes a decrease in activity. This becomes most significant when $75 \%$ of water was added (TOF drops from $2980 \mathrm{~h}^{-1}$ to $840 \mathrm{~h}^{-1}$ ). The effect on selectivity, however, was negligible. $61-62 \%$ selectivity to benzaldehyde at $90 \%$ conversion (S90) was obtained in both cases. Here toluene was the main by-product due to a hydrogen transfer process. Indeed Pd is a well known catalyst for this type of reaction [22]. Prior to perform the reaction in organic solvent (cyclohexane) we carried out blank experiment that proved the inertness of cyclohexane under the actual reaction condition. As reported in Table 2, a 20\% vol. addition of cyclohexane did not modified the result of solventless experiment, but when the amount of solvent increased, the expected decreasing of the reaction rate was accompanied by a huge improving in selectivity. By increasing the cyclohexane amount from 50 to $80 \%$, we observed a strong enhancement in aldehyde selectivity and a consistent decreasing in the toluene one.

Comparing the TOFs of $\mathrm{Pd} / \mathrm{CNT}$ s with that of $\mathrm{Pd} / \mathrm{AC}$ (Table 2) we could generally observe that Pd on CNTs showed a lower activity than Pd/AC. However the most interesting point came from the selectivity. In the solventless reaction $\mathrm{Pd} / \mathrm{CNT}$ s exhibited a considerably higher selectivity to aldehyde with respect to the one obtained with $\mathrm{Pd} / \mathrm{AC}$ (S90 78\% versus $61 \%$ ). When water was added, a decrease of selectivity to aldehyde was observed. This trend became more serious when water content was at 50$75 \%$. Meanwhile the toluene formation increased. On the contrary, when cyclohexane was added we obtained a remarkable enhancement of benzaldehyde production with selectivity higher than $90 \%$ with $50 \%$ vol. solvent. In this latter case it should be noted that the activity of the catalyst is quite good $\left(1340 \mathrm{~h}^{-1}\right)$ being comparable with the one of $\mathrm{Pd} / \mathrm{AC}$ (TOF $1482 \mathrm{~h}^{-1}$ ).

On the basis of these results we can conclude that performances of both catalysts ( $\mathrm{Pd} / \mathrm{AC}$ and $\mathrm{Pd} / \mathrm{CNTs})$ are very sensitive to the solvent employed and that in both cases the addition of a solvent decreased the catalyst activity compared to solventless conditions. Cyclohexane with respect to water appeared to be more able to preserve the activity. However the main positive effect of solvent is to improve the selectivity to aldehyde, this effect being slightly higher for Pd on CNTs than on AC.

\subsection{Catalyst durability (recycling test)}

From an applicative point of view, one of the most appreciable properties of a heterogeneous catalyst is its durability. Thus we tested the Pd on AC and on CNTs catalysts on recycling, checking the overall leaching of the $\mathrm{Pd}$ or any other modification on the used catalyst after several runs. Each run was carried out under identical conditions (alcohol $/$ metal 3000/1 (mol $/ \mathrm{mol}), 80^{\circ} \mathrm{C}, p \mathrm{O}_{2} 2$ atm, 1250 rpm, cyclohexane 50\%vol.) and reusing the catalyst recovered by filtering off the solution of the previous run after 1h. After 7 runs, despite the selectivity did not change so far, conversion after one hour has declined about $70 \%$ in the case of Pd/AC (Figure 3a) and $47 \%$ in the case of $\mathrm{Pd} / \mathrm{CNTs}$ (Figure $3 \mathrm{~b}$ ). A reason of this behaviour can be found in the characterisation of the recovered catalysts which have been observed by TEM after washing with water and dried. In both case a growing in size of Pd particles was observed which are expected to show lower active
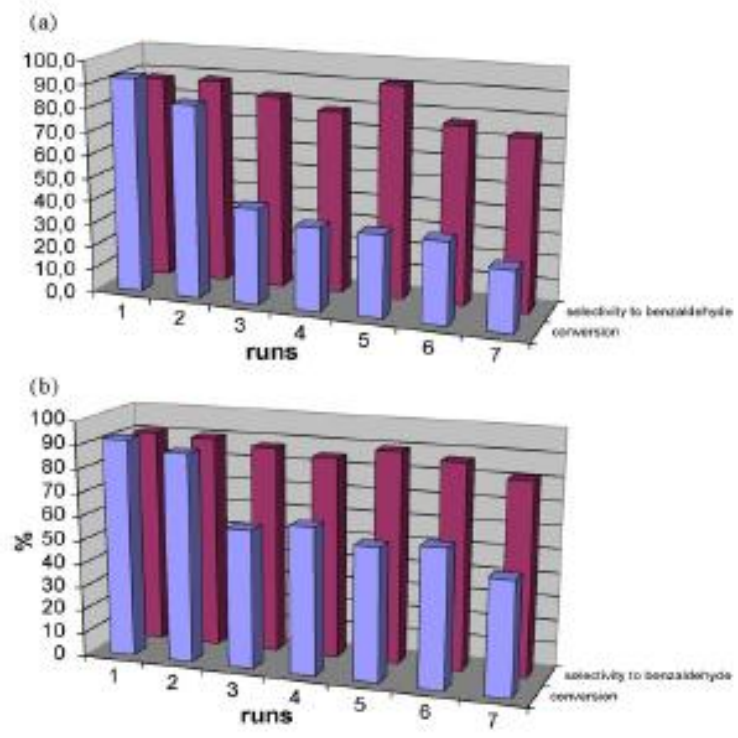

Fig. 3: a) Conversion/selectivity on recycling $1 \% \mathrm{Pd} / \mathrm{AC}$, b) Conversion/selectivity on recycling $1 \% \mathrm{Pd} / \mathrm{CNTs}$ 

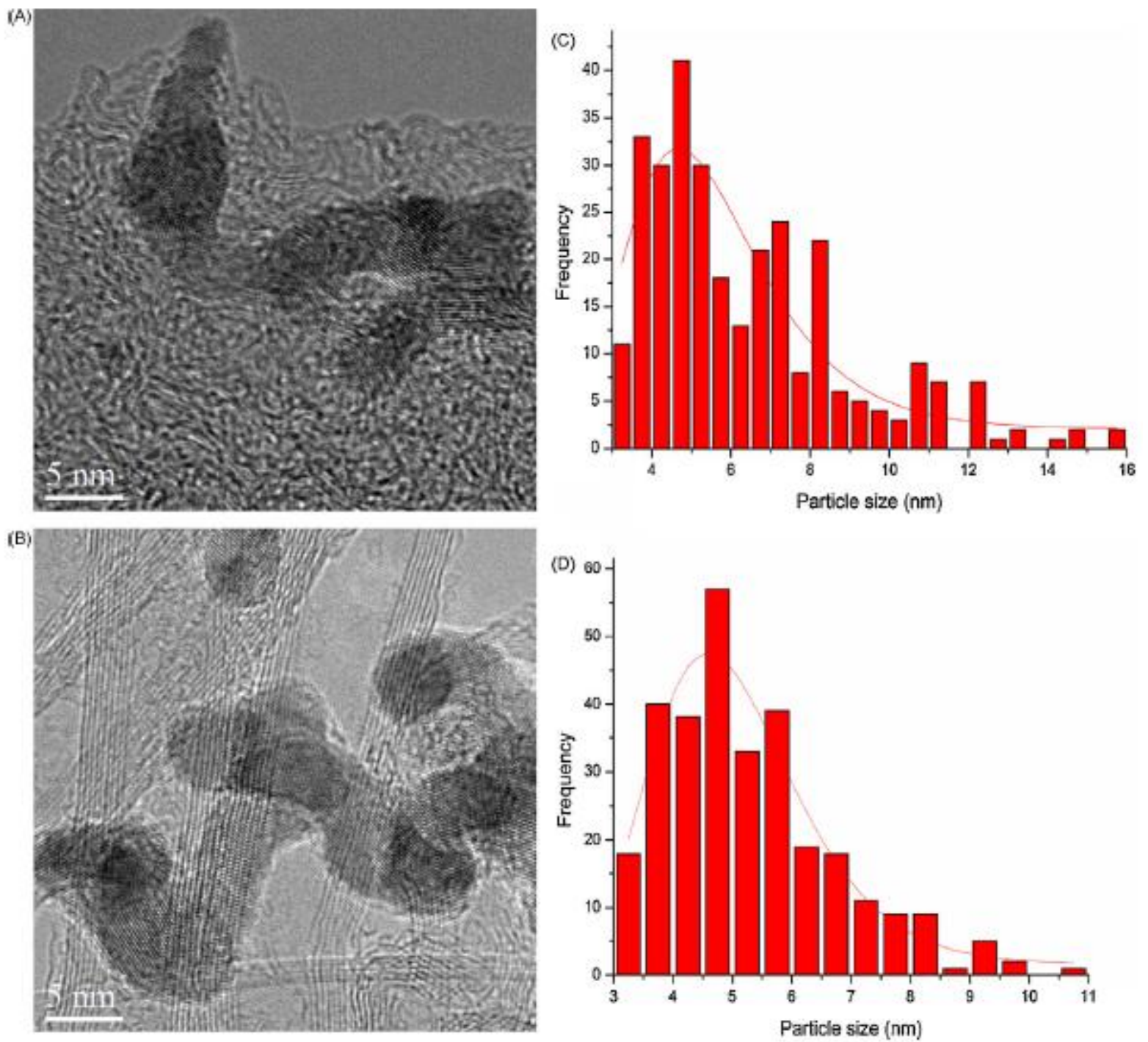

Fig. 4: The TEM overview image for Pd/AC and (b) Pd/CNTs after reaction. Pd particle size distribution of c) Pd/AC and d) Pd/CNTs after reaction.

ity than the one of smaller, highly dispersed particles (Figures $4 \mathrm{a}$ and $\mathrm{b}$ and Table 1). Figures $4 \mathrm{c}$ and $\mathrm{d}$ show the particle size distribution of the $\mathrm{Pd} / \mathrm{CNTs}$ and $\mathrm{Pd} / \mathrm{AC}$ after reaction, in which the median particle size are $6.4 \mathrm{~nm}$ and $5.3 \mathrm{~nm}$ respectively (Table 1 ), considerably larger than for the corresponding fresh catalysts. Apart from the aggregates, a considerable number of the particles were observed to undergo coalescence to form big and irregularly shaped particles. Moreover, we performed ICP analysis on the used catalysts, after burning off the carbonaceous material, detecting a consistent leaching of $\mathrm{Pd}(28 \%$ for $\mathrm{Pd} / \mathrm{AC}$ and $25 \%$ for $\mathrm{Pd} / \mathrm{CNTs}$ ). All these factors lead to the drastic reduction of the accessible reaction sites on $\mathrm{Pd}$. We can then conclude that these systems are not stable under the reaction conditions used and need to be stabilised for an industrial exploitation. Moreover, considering that the selectivity has not changed during the recycled runs, we also concluded that the selectivity is independent on the particle size range we have investigated. Therefore the difference in selectivity between $\mathrm{Pd} / \mathrm{AC}$ and $\mathrm{Pd} / \mathrm{CNT}$ s is expected to relate with the support properties and their influences on the Pd sites.

We already experienced the beneficial effect of alloying gold to Pd nanoparticles [23]. A two step procedure that ensures the formation of uniform alloyed $\mathrm{Pd} / \mathrm{Au}$ nanoparticles on AC has been published [15] and proved to enhance both activity and durability of the catalyst in glycerol oxidation [23]. As we were interested to improve the catalyst stability, we now extended the same technique to prepare bimetallic Au-Pd nanoparticles on CNTs and thus allowing comparing the behaviour of $\mathrm{Au}-\mathrm{Pd}$ on $\mathrm{AC}$ with that of Au-Pd on CNTs. The resulted catalysts show similar particle size, $3.4 \mathrm{~nm}$ for $\mathrm{Au}-\mathrm{Pd} / \mathrm{AC}$ and $3.5 \mathrm{~nm}$ for $\mathrm{Au}-$ $\mathrm{Pd} / \mathrm{CNTs}$ (Table 1), even differently distributed.(Figures 5c and d). Preliminary tests for evaluating the real effect of the adding of $\mathrm{Au}$ to $\mathrm{Pd}$ were performed in cyclohexane (50\%vol) that, as outlined before, strongly differs from water as solvent and in that also $\mathrm{Au}-\mathrm{Pd} / \mathrm{AC}$ was never used 

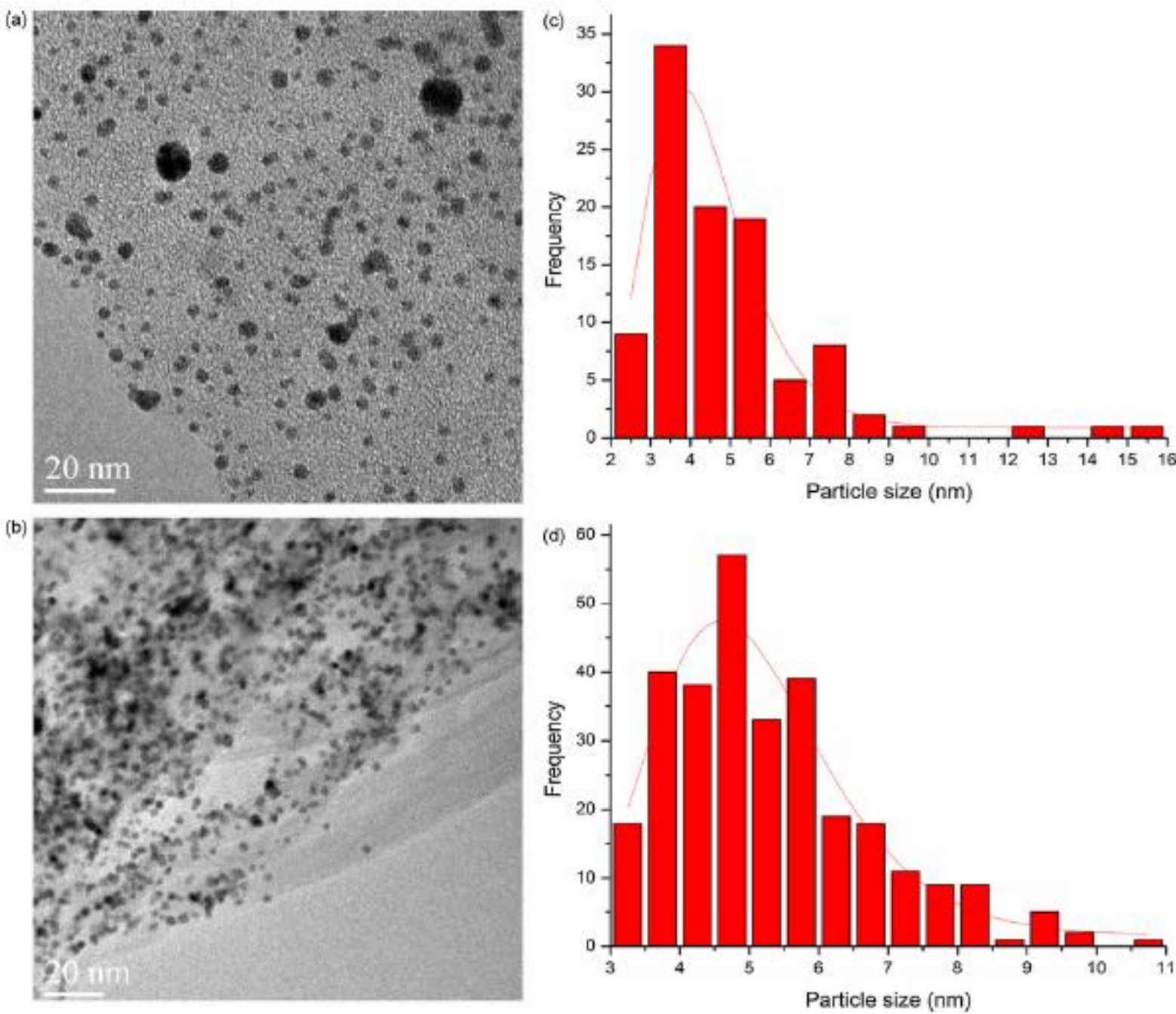

Fig. 5: HRTEM of a) Au-Pd/AC and AC and b) Au-Pd/CNTs. Particle size distribution of c) Au-Pd/AC and d) Au-Pd/CNTs

Table 3. Comparison of mono and bi-metallic catalyst activities in benzyl alcohol oxidation

\begin{tabular}{lllc}
\hline & $\begin{array}{l}\text { Selectivity } \\
\text { to bluene }\end{array}$ & $\begin{array}{l}\text { Selectivity } \\
\text { to benzaldehyde }\end{array}$ & TOF $^{*}\left(\mathrm{~h}^{-1}\right)^{p}$ \\
\hline Pd/AC & 23 & 74 & 1482 \\
Au/AC & - & - & $<1$ \\
Au-Pd/AC & 9 & 89 & 1350 \\
Pd/CNIs & 3 & 92 & 1340 \\
Au/CNIs & - & - & $<1$ \\
Au-Pd/CNTs & 3 & 89 & 1490 \\
\hline
\end{tabular}

Reaction condition: alcohol/metal 3000/1 $(\mathrm{mol} / \mathrm{mol}), 80^{\circ} \mathrm{C}$, solvent:cyclohexane 50\%vol., $p \mathrm{O}_{2} 2$ atm, $1250 \mathrm{rpm}$

${ }^{\text {a }}$ Selectivity at $90 \%$ conversion

${ }^{\mathrm{b}}$ TOF calculated after $15 \mathrm{~min}$ of reaction

in the past [23]. Table 3 reports the activities of mono metallic catalysts compared to bimetallic Au-Pd ones. Under these conditions monometallic gold resulted inactive both supported on AC and CNTs. This behaviour did not surprise as gold it is expected to be an active catalyst under basic conditions. Moreover we were quite disappointed to observe that Pd and Au-Pd showed, under these experimental conditions, a similar behaviour from both activity and selectivity point of view. In fact only a slight variation of TOFs was obtained: from 1482 to $1350 \mathrm{~h}^{-1}$ for $\mathrm{AC}$ and from 1340 to $1490 \mathrm{~h}^{-1}$ for CNTs. Selectivity to benzaldehyde only improved in the case of Au-Pd on AC compared to $\mathrm{Pd} / \mathrm{AC}$.

On the contrary a completely different catalytic behaviour was highlighted on recycling. Under the same conditions as for the test of monometallic $\mathrm{Pd}, \mathrm{Au} / \mathrm{Pd}$ on $\mathrm{AC}$ losses in 8 runs about $50 \%$ of its activity whereas CNTs only $4 \%$ (Figure 6a and b). ICP measurements revealed a leaching of palladium of $10 \%$ for $\mathrm{Au}-\mathrm{Pd} / \mathrm{AC}$ whereas only $4 \%$ in the case of $\mathrm{Au}-\mathrm{Pd} / \mathrm{CNTs}$. In both cases leaching of $\mathrm{Au}$ resulted negligible. Considering the normal loss of the catalyst i.e. the expected decreasing in conversion due to the reduced amount of catalyst recovered from any subsequent run (3-4\%), the leaching of $\mathrm{Pd}$ is inconsistent with both of catalytic results. However we already observed that the leaching of Pd depends on particle size [23]. This different leaching could create the presence of different alloy composition that could possibly show different activity. This was already observed in the case of aqueous glycerol 

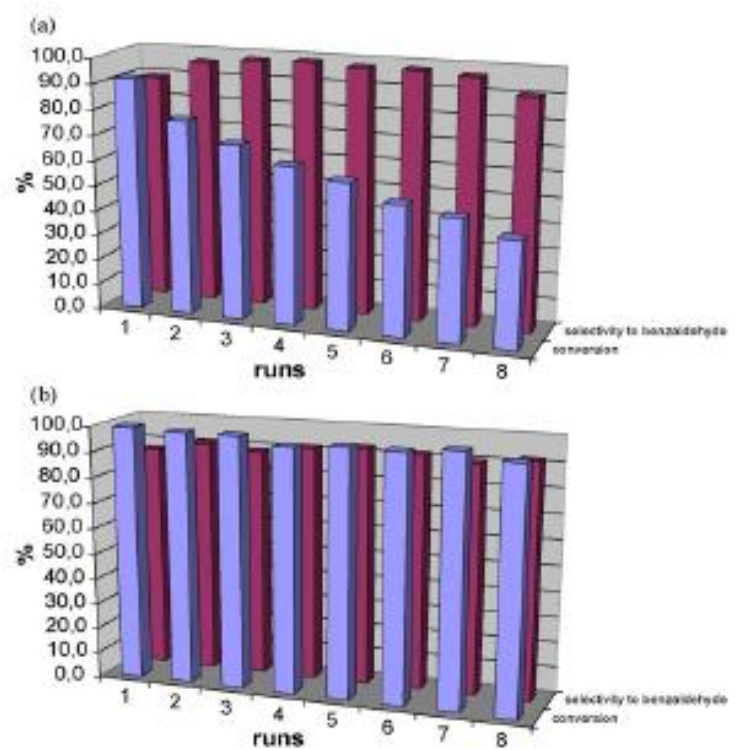

Fig. 6: a) Conversion/selectivity on recycling of $1 \% \mathrm{Au}-\mathrm{Pd} / \mathrm{AC}$. b) Conversion/selectivity on recycling of $1 \% \mathrm{Au}-\mathrm{Pd} / \mathrm{CNTs}$

oxidation where the maximum of activity was reached for $\mathrm{Au}_{95} \mathrm{Pd}_{05}$ composition [24]. At this stage we could only conclude that gold stabilizes the palladium more efficiently on CNTs than on active carbon. Further studies are needed to determine the nature of this stabilisation.

\section{Conclusions}

We compared the activity of Pd nanoparticles supported on AC and CNTs in the liquid phase oxidation of benzylic alcohol to benzaldehyde. Although we used a procedure (sol immobilisation) that in principle assures a similar distribution on different supports, we obtained a slight different metal distribution in the two cases. Pd nanoparticles on CNTs are smaller in size but less dispersed than on AC. Catalytic test revealed that Pd supported on CNTs behaves differently from Pd on AC. In fact, the expected lower activity of Pd/CNTs according to the lower metal dispersion was related to a higher selectivity toward benzaldehyde strongly dependent on the solvent used. The maximum of selectivity $(92 \%)$ was obtained for a $50 \%$ volume of cyclohexane as solvent. The use of Pd on both AC and CNTs is however limited by the high Pd leaching revealed on recycling (28 and $25 \%$ respectively). A consistent improving in the long-term use of the catalysts has been obtained by modifying the monometallic Pd with gold. With this purpose the procedure set up for producing Au-Pd alloyed nanoparticles on AC was extended to CNTs. On recycling this latter catalyst showed limited Pd leaching and stable catalytic performances over 8 runs. Under similar conditions Au-Pd on $\mathrm{AC}$ resulted less stable.

\section{Acknowledgements}

Authors thanks DAAD, Programma Vigoni and Fondazione Cariplo for financial support

\section{References}

[1] T.Mallat, A.Baiker, Chem.Rev. 104 (2004) 3037.

[2] M. Besson, P. Gallezot, Catal .Taoday, 57 (2000) 127

[3] R.A. Sheldon, I.W.C.E. Arends, G.J. ten Brink, A. Dijksman, Acc. Chem. Res. 35 (2002) 774.

[4] B.A. Steinhoff, S.R. Fix, S.S. Stahl, J. Am. Chem. Soc. 124 (2002) 766

[5] T. Nishimura, Y. Maeda, N. Kaikiuchi, S. Uemura, J. Chem. Soc. Perkin Trans. 1 (2000) 4301.

[6] Z. Liu, X. Lin, J. Y. Lee, W. Zhang, M. Han, L.M. Gan, Langmuir 18 (2002) 4054.

[7] Y. Xing, J. Phys Chem B. 108 (2004) 19255.

[8] H.-S. Kim, H. Lee, K.-S. Han, J.-H. Kim, M.-S. Song, M.-S. Park,J.-Y. Lee, J.-K. Kang, J.Phys.Chem. B 109 (2005), 8983.

[9] J.-Y. Lee, H. Lee, H.-S. Kim, Mater. Sci. Forum 475-479 (2005) 2463.

[10] Kong, M. G. Chapline, H. Dai, Adv. Mater. 13 (2001) 1384.

[11] J.P. Tessonier, L. Pesant, G. Ehret, M.J. Ledoux, C. PhamHuu, Appl.Catal.A 288 (2005) 203.

[12] H. Vu, F. Goncalves, R. Philippe, E. Lamouroux, M. Corrias, Y. Kihn, D. Plee, P. Kalck, P. Serp, J. Catal. 240 (2006) 18.

[13] A. Corma, H. Garcia, A. Leyva, J Mol Catal. A 230 (2005) 97.

[14] N. Karaousis, G. Tsotsou, F. Evangelista, P. Rudolf, N. Ragoussis, N. Tagmatarchis, J.Phys.Chem. C 112 (2008) 13463.

[15] D. Wang, A. Villa, F. Porta, D. Su, L. Prati, Chemm. Commun. (2006) 1956.

[16] S. Demeril, K. Lehnert, M. Lucas, P. Claus, Appl. Catal B, 70 (2007) 637

[17] D.I. Enache, J.K. Edwards, P. Landon, B. Solsona-Espriu, A.F. Carley, A.A. Herzing, M. Watanabe, C.J. Kiely, D.W. Knight and G.J. Hutchings, Science 11 (2006) 362.

[18] N. Dimitratos, A. Villa, D. Wang, F. Porta, D. Su and L. Prati, J. Catal 244 (2006) 113

[19] W. Hou, N.A.Dehm, R.W.J. Scott, J. Catal. 253 (2008) 22

[20] H. P. Boehm, Advances in Catalysis; Academic Press: New York, 1966; Vol. 16

[21] C. Della Pina, E. Falletta, L. Prati, M. Rossi, Chem. Soc. Rev. 37 (2008) 2077 and references cited therein.

[22] [J.M.Thomas, W.J.Thomas Principles and Practice of Heterogeneous Catalysis VHC Ed, Weinheim, Germany, 1997

[23] L. Prati, A.Villa , F. Porta , D. Wang , D. Su, Catal.Today 122 (2007) 386.

[24] D.Wang, A.Villa,, F. Porta,L. Prati, D. Su, J. Phys. Chem. C 112 (2008) 8617 